\title{
Communications
}

\section{How Long the Wait until We Can Call It Television}

Jerry BORRELL: Congressional Research Service, Library of Congress, Washington, D.C.*

This brief article will review videotex and teletext. There is little need to define terminology because new hybrid systems are being devised almost constantly (hats off to OCLC's latest buzzword-Viewtel). Most useful of all would be an examination of the types of technology being used for information provision. The basic requirement for all systems is a data base-i.e., data stored so as to allow its retrieval and display on a television screen. The interactions between the computer and the television screens are means to distinguish technologies. In teletext and videotex a device known as a decoder uses data encoded onto the lines of a broadcast signal (whatever the medium of transmission) to generate the display screen. In videotex, voice grade telephone lines or interactive cable are used to carry data communications between two points (usually 1200 baud from the computer and 300 baud or less from the decoder and the television screen). In teletext the signal is broadcast over airwaves (wideband) or via a time-sharing system (narrowband). The numerous configurations possible make straightforward classification of systems questionable.

A review of the systems currently available is useful to illustrate these terms, videotex and teletext. CompuServe, the Columbus, Ohio-based company, provides on-line searching of newspapers to about 4,000 users. Reader's Digest recently acquired 51 percent of The Source, a time-

*The views expressed in this paper do not necessarily represent those of the Library of Congress or of the Congressional Research Service. sharing service that provides more than 100 different (nonbibliographic) data bases to about 5,000 users. The Warner and American Express joint project, QUBE (also Columbus-based), utilizes cable broadcast with a limited interactive capability. It does not allow for on-demand provision of information; rather, it uses a polling technique. Antiope, the French teletext system, used at KSL in St. Louis last year and undergoing further tests in Los Angeles at KNXT in the coming year, is only part of a complex data transmission system known as DIDon. Antiope is also at an experimental stage in France, with 2,500 terminals scheduled for use in 1981 .

CEEFAX and Oracle, broadcast teletext by the $\mathrm{BBC}$ and $\mathrm{IBC}$ in Britain, have an estimated 100,000 users currently. Two thousand adapted television sets are being sold every month. Prestel, BBC's videotex system, currently has approximately 5,000 users, half of whom are businesses.

All other countries in Europe are conducting experiments with one of the technologies. In Canada, Telidon, the most technically advanced system, has 200 users. Experiments involving Telidon are being conducted nationwide due to government interest in telecommunications improvements. Telidon will also be used in Washington in the spring of 1981 for consumer evaluation.

These cursory notes should indicate the breadth of interest in alternative means of information provision. Video and electronic publishing newsletters (see references) keep track of the number of users and are the best way to keep informed of activities and developments.

Several important trends are becoming evident. Perhaps the most evident is the realization that videography is being developed in countries other than the U.S. 
as a result of strong support by the National Posts and Telecommunications (PTT) authorities. Until recently there was a feeling that the U.S. was technically behind Europe. What is now evident is that in the free market system of the U.S. manufacturers or other potential system providers have had insufficient impetus to provide videotex/teletext technology. The technology of information display (see Borrell, Journal of Library Automation, V.13 (Dec. 1980), p.277-81) in the U.S. is an order of magnitude more sophisticated than in Europe. The point being that in the absence of strong PTT pressure, videography in the U.S. developed for specialized markets in which telecommunications were not a central need. In the one area of great demand, teletext services for the hearing impaired, decoders were developed and have been employed for a number of years (about 25,000 are currently in use). As the high cost of telecommunications bandwidth is eased by data compression, direct broadcasting by satellite, enhanced cable services, and fiber optic networks, then videotex and teletext will become available on a wide scale in the U.S.

The Computer Inquiry II decision by the FCC involving reinterpretation of the Communications Act of 1934 has given AT\&T permission to enter the data processing market. In fact, AT\&T, in its third experiment with videotex, is taking such an aggressive stance that it seems to be doing everything that its critics have feared: providing updatable classified ads (dynamic yellow pages), allowing users to place information into the system memory, and providing voice mail servicesthereby taking on the newspapers, home computer manufacturers, and the U.S. Postal Service. In addition, banking services will be offered. As the largest company in the U.S., this stance cannot be ignored. AT\&T supplies about 80 percent of the phone service in the U.S., and has the potential, if allowed, to become a broadcaster, data processor, publisher, and banker; cross-ownership was never allowed up to this time.

The trend toward specialized services provision is also exemplified by the
French and British systems. Prestel, which was originally targeted for a home market, is now promoted with the tacit policy of being a special business service allowing financial and private data to be provided to subscribers. Sofratev, the marketers of the French teletext system, are acknowledging the importance of transactional markets in two ways, based on technology they have named "smart card," a credit card-size (in one configuration) plate with a built-in microprocessor or chip. The card will allow system users to access material that will have controlled readership. An example would be a magazine of financial data provided to those who need such information (or, more importantly, are willing to pay for it). In a more complex effort, the largest retailer in Paris will advertise material via teletext and system users will be able to make acquisitions with their smart card, which can be programmed with financial data.

Nor is this the end of the effort by the French to market information display technology. The electronic phone directory, being offered by Bell in Austin, is replicated in a more modest way by the French, who plan to produce a six-byeight-inch black-and-white display unit that will provide phone directory information (both white and yellow pages) to all of France by the 1990s. Developed as part of the "Telematique" program of the French government, the terminals represent to some (the parent company of The Source has tendered an offer for up to 250,000 of the terminals) a low-cost alternative for providing videotex to a mass market. The Tandy home computer in its videotex configuration seems to fill the same market slot.

Perhaps the most disturbing trend, at least from a librarian's point of view, is the fact that contemporary data systems are being created which could benefit greatly from the experience of librarians and libraries. For instance, research into the methods of access-keyword, phonetic and geographical-by the French is intended to provide a flexible and easily used system for untrained persons searching for directory information, and is being performed by an advertising and yellow pages 
publishing firm. With a feeling of déjà vu I listened to an explanation of how difficult it is to develop a system for the novice; one proposed solution is to allow only the first four letters of a word to be entered (one of the search methods used at the Library of Congress, which does suggest some cross-fertilization).

Whatever the trends, the reality is that librarians and information scientists are playing decreasing roles in the growth of information display technology. Hardware systems analysts, advertisers, and communications specialists are the main professions that have an active role to play in the information age. Perhaps the answer is an immediate and radical change in the training of library schools of today. Our small role may reflect our penchant to be collectors, archivists, and guardians of the information repositories. Have we become the keepers of the system? The demand today is for service, information, and entertainment. If we librarians cannot fulfill these needs our places are not assured.

Should the American Library Association (ALA) be ensuring that libraries are a part of all ongoing tests of videotex - at least in some way-either as organizers, information providers, or in analysis? Consider the force of the argument given at the ALA 1980 New York Annual Conference that cable television should be a medium that librarians become involved with for the future. Certainly involvement is an important role, but we, like the industrialists and marketers before us, must make smart decisions and choose the proper niche and the most effective way to use our limited resources if we are to serve any part of society in the future.

\section{BIBLIOGRAPHY}

1. Electronic Publishing Review. Oxford, England: Learned Information Ltd. Quarterly.

2. Home Video Report. White Plains, New York: Knowledge Industry Publications. Weekly.

3. IEEE Transactions on Consumer Electronics. New York: IEEE Broadcast, Cable, and Consumer Electronics Society. Five times yearly.

4. International Videotex/Teletext News. Washington, D.C.: Arlen Communications Ltd. Monthly.
5. Videodisc/Teletext News. Westport, Conn. Microform Review. Quarterly.

6. Videoprint. Norwalk, Conn.: Videoprint. Two times monthly.

7. Viewdata/Videotex Report. New York: Link Resources Corp. Monthly.

\section{Data Processing Library: A Very Special Library}

Sherry COOK, Mercedes DUMLAO, and Maria SZABO: Bechtel Data Processing Library, San Francisco, California.

The 1980s are here and with them comes the ever broadening application of the computer. This presents a new challenge to libraries. What do we do with all these computer codes? How do we index the material? And most importantly, how do we make it accessible to our patrons or computer users?

Bechtel's Data Processing Library has met these demands. The genesis for the collection was Bechtel's conversion from a Honeywell 6000 computer to a Univac 1100 in 1974. All the programs in use at that time were converted to run on the Univac system. It seemed a good time to put all of the computer programs together from all of the various Bechtel divisions into a controlled collection. The librarians were charged with the responsibility of enforcing standards and control of Bechtel's computer programs.

The major benefits derived from placing all computer programs into a controlled library were:

1. Company-wide usage of the programs.

2. Minimize investment in program development through common usage.

3. Computer file and documentation storage by the library to safeguard the investment.

4. Central location for audits of program code and documentation.

5. Centralized reporting on Bechtel programs.

Developing the collection involved basic cataloging techniques which were greatly modified to encompass all the information that computer programs generate, including actual code, documentation, and list- 